\title{
European adolescent ready-to-eat-cereal (RTEC) consumers have a healthier dietary intake and body composition compared with non-RTEC consumers
}

\author{
Nathalie Michels · Stefaan De Henauw • Christina Breidenassel • Laura Censi • Magdalena Cuenca-Garcí • \\ Marcela Gonzalez-Gross • Frederic Gottrand • Lena Hallstrom • Anthony Kafatos • Mathilde Kersting • \\ Yannis Manios • Ascension Marcos • Denes Molnar $\cdot$ Luis A. Moreno $\cdot$ Maria Plada $\cdot$ Michael Sjostrom • \\ Béatrice Reye $\cdot$ Frank Thielecke $\cdot$ Jara Valtueña $\cdot$ Kurt Widhalm $\cdot$ Mandy Claessens
}

Received: 25 September 2014 / Accepted: 11 November 2014 / Published online: 18 November 2014

(C) Springer-Verlag Berlin Heidelberg 2014

\begin{abstract}
Purpose This study aims to analyse the association of European adolescents' ready-to-eat-cereal (RTEC) consumption frequency with their dietary intake by applying the concept of diet quality index and nutritional status.

Methods From the multi-centre European HELENA study, relevant data were available in 1,215 adolescents (12.5-17.5 years). RTEC consumption was identified from a food frequency questionnaire. A diet quality index, daily nutrient intakes and daily milk/yoghurt and fruit intake
\end{abstract}

N. Michels $(\square) \cdot S$. De Henauw $\cdot$ M. Claessens

Department of Public Health, Ghent University, De Pintelaan 185 - 4K3, 9000 Ghent, Belgium

e-mail: Nathalie.michels@ugent.be

S. De Henauw

Department of Health Sciences, Vesalius, Hogeschool Gent,

Ghent, Belgium

C. Breidenassel

Institut für Ernährungs- und Lebensmittelwissenschaften-

Humanernährung, Rheinische Friedrich-Wilhelms Universität,

Bonn, Germany

L. Censi

Agricultural Research Council, Food and Nutrition Research

Centre (CRA-NUT), Rome, Italy

M. Cuenca-Garcí

Department of Medical Physiology, School of Medicine, Granada

University, Granada, Spain

M. Gonzalez-Gross · J. Valtueña

ImFine Research Group, Department of Health and Human

Performance, Faculty of Physical Activity and Sport Sciences

(INEF), Universidad Politécnica de Madrid, Madrid, Spain

F. Gottrand

Inserm U995, Université Lille 2, Lille, France were calculated from two 24-h dietary recalls. BMI, waist and hip circumference and body fat were measured for body composition. Cross-sectional regression analyses were adjusted for sex, age, socio-economic status, city and breakfast skipping. Differences in sub-regions within Europe were explored.

Results RTEC consumers showed a more favourable daily micronutrient intake (vitamin B2, B5, B7, D, calcium, phosphorus and potassium), a better diet quality index, more frequent fruit (57 vs. $51 \%$ ) and milk/yoghurt

\section{Hallstrom \\ School of Health, Care and Social Welfare, Mälardalen University, Västerås, Sweden}

L. Hallstrom · M. Sjostrom

Department of Biosciences and Nutrition, Karolinska Institutet, Huddinge, Stockholm, Sweden

\section{A. Kafatos · M. Plada}

Department of Social Medicine, Preventive Medicine and Nutrition Clinic, University of Crete School of Medicine, Heraklion, Crete, Greece

\section{Kersting}

Research Institute of Child Nutrition, Dortmund, Rheinische Friedrich-Wilhelms-Universität Bonn, Bonn, Germany

Y. Manios

Department of Nutrition and Dietetics, Harokopio University, 70 El. Venizelou ave, 17671 Athens, Greece

\section{A. Marcos}

Institute of Food Science and Technology and Nutrition, Spanish National Research Council, Madrid, Spain

D. Molnar

Department of Paediatrics, Medical Faculty, University of Pecs, Pecs, Hungary 
consumption (81.2 vs. $56 \%$ ) and less breakfast skipping (25.1 vs. $36.7 \%)$. No differences in energy and macronutrient intake were observed. Daily RTEC consumers were $57 \%$ less likely to be overweight than RTEC non-consumers but did not differ in glucose and lipid status $(N=387)$. Conclusion This is the first comprehensive pan-European survey elucidating socio-demographic determinants of European adolescents' RTEC consumption and indicating better dietary habits in RTEC consumers. The improved dietary profile was reflected in a more beneficial body composition. Our results have also shown the advantage of using an all-integrating diet quality index by capturing the diet complexity.

Keywords Adolescents - Ready-to-eat-cereals · Diet quality index · Overweight · Glucose homoeostasis . Blood lipids

\section{Introduction}

Ready-to-eat-cereals (RTEC) can be defined as a cereal food that is processed to the point where it can be eaten without further preparation (although milk is usually added). RTEC become increasingly popular because of the convenience, the long shelf-life and the attractive variety in choice. They have been commercialised as healthy due to its fibre content and some varieties made with whole grain, as well as the stimulation of milk consumption. Moreover, most RTEC are fortified with a range of micronutrients including B vitamins and iron $[1,2]$.

Consequently, several studies already quoted the beneficial daily nutrient intake of RTEC consumers [3-10]: less fat, more fibre, vitamins and minerals but sometimes also higher sugars intake. To the authors' knowledge, no

\section{A. Moreno}

GENUD (Growth, Exercise, Nutrition and Development)

Research Group, School of Health Sciences, University

of Zaragoza, Domingo Miral s/n, 50009 Saragossa, Spain

B. Reye $\cdot$ F. Thielecke

Cereal Partners Worldwide S.A., Lausanne, Switzerland

F. Thielecke

Nestlé Research Center, Vers chez les Blanc, Lausanne,

Switzerland

K. Widhalm

Department of Pediatrics, Private Medical University Salzburg, Salzburg, Austria

K. Widhalm

Division for Clinical Nutrition, Obesity and Lipoprotein Disorders, Department of Pediatrics, Medical University of Vienna, Vienna, Austria previous studies have used a whole day diet quality index (DQI) in children/adolescents, although such an index is more capable to capture the diet complexity in a single value and to predict health outcomes [11].

If RTEC consumers have healthier dietary intakes, RTEC consumption may be related to broader health parameters such as biomarker status and body composition. Indeed, two recent meta-analyses showed that RTEC are associated with lower obesity figures in children and adolescents [12, 13]. It should be noted that these studies mainly focused on the body mass index (BMI) and less on the explicit body fat percentage or on central adiposity. Some studies in adolescents tried to find associations with serum lipid levels, although with variable success: they found no association [8], only lower total cholesterol $[6,14]$ or lower low-density lipoprotein cholesterol levels [3]. Seldom, RTEC consumption has also been associated with other biomarkers such as lower glucose levels [8].

This study aims to analyse the association of RTEC intake with dietary intake and nutritional status in adolescents, independently of breakfast consumption or skipping. Correction herein for breakfast skipping is important since RTEC are often eaten at breakfast and since breakfast skipping has been associated with poor diet, elevated lipids, disturbed glucose homoeostasis and enhanced risk for obesity $[12,15-18]$. Our research questions were (a) what are the socio-demographic determinants of RTEC consumption in European adolescents; (b) do occasional, frequent and daily RTEC consuming adolescents have different dietary habits (e.g. nutrients intake, fruit and milk/yogurt consumption and overall dietary quality) compared with non-consumers; (c) do RTEC consumers have different nutritional status concerning body composition, glucose metabolism and blood lipids than non-consumers. Where possible, regional differences in the pan-European survey were described. For this purpose, data of the "Healthy Lifestyle in Europe by Nutrition in Adolescence" (HELENA) study were used. HELENA is the first large-scale multi-centric European survey with harmonised methodology to provide data about attitudes towards nutrition and the main determinants and consequences of food choice among European adolescents.

\section{Methods}

Population

The HELENA cross-sectional study is a population-based, multi-centre investigation of the nutritional and lifestyle status of adolescents, carried out in ten European cities (Vienna in Austria, Ghent in Belgium, Lille in France, Dortmund in Germany, Athens and Heraklion in Greece, Pecs in Hungary, Rome in Italy, Zaragoza in Spain and 
Stockholm in Sweden). Data were collected from October 2006 to December 2007. A detailed description of the HELENA study design and sampling procedure has been published elsewhere $[19,20]$. The study was approved by the ethical committees and performed following the ethical guidelines of the Declaration of Helsinki. All study participants and their parents provided a signed informed consent form.

The total HELENA population consisted of 3,528 eligible adolescents ( $52.3 \%$ females) aged $12.5-17.5$ years. For the current analyses, adolescents were included if data were available for two non-consecutive 24-h dietary recalls and the food frequency questionnaire (FFQ), resulting in 1,215 eligible subjects. Since for Heraklion, Pecs and Rome no full set of dietary data were available (i.e. two 24-h dietary recalls and a FFQ), subjects from these cities were excluded from the present study. In the HELENA population, non-participants did not differ in sex or age. For this paper, age and BMI did not differ between excluded and included cases, while less boys and more adolescents from high socio-economic status (SES) were included ( $p=0.002$ and $p=0.010$, respectively). Data on glucose and lipid homoeostasis were only available in a subpopulation $(N=387)$; they did not differ in sex, BMI and SES but had a higher age ( $p<0.001$; mean 14.5 vs. 14.2 years) compared with the other eligible subjects.

Socio-demographic determinants

Collected demographic data included information on sex, age, city and SES by means of a standardised self-reported questionnaire. SES was examined by parental education and by the Family Affluence Scale (FAS). Education level of mother and father was reported as "lower education", "higher secondary education" and "university education". A modified version of the FAS developed by Currie et al. [21] was used as a proxy of SES status; the scale is based on the concept of material conditions in the family. For the purposes of the HELENA study, the FAS was slightly modified by replacing the item on frequency of family holidays by Internet availability at home. The adolescents completed a questionnaire asking about the number of cars (0-3 depending on amount) and computers at home (0-3 depending on amount), having access to Internet at home ( 0 no, 1 yes), and whether the adolescent had his or her own room (0 no, 1 yes). Adolescents were scored from 0 (very low SES) to 8 (very high SES). For some analyses, countries were organised in geographical regions, as agreed on in the HELENA study: Greece, Italy and Spain represented the "Southern" region (Mediterranean); (2) Sweden and Belgium represented the "Northern" regions and (3) France, Germany and Austria represented the "West/central" region.
Diet

FFQ to assess RTEC consumption and breakfast skipping

The FFQ [22] consisted of 15 items of which participants had to indicate the frequency of eating by ticking one of the following seven responses: (1) never; (2) rarely, less than once a week; (3) once a week; (4) 2-4 times a week; (5) 5-6 times a week; (6) once a day/every day; and (7) more than once a day/every day. The cereal item (such as cornflakes, muesli and chocolatey cereals) was used to represent RTEC intake. Adolescents were classified as RTEC consumer when they reported RTEC consumption once a week or more (=answer possibilities 3 up to 7). To further analyse RTEC consumption frequency, a categorical variable with four RTEC categories was created: non-consumer (never or less than once a week), occasional consumer (once a week), frequent consumer (2-4 times a week) and daily consumer (5-6 times a week, once a day or every day). The 24-h dietary recall data are more precise than food frequency data due to information on quantification and meal occasion. Nevertheless, 24-h recall data have not been used for RTEC consumption categorisation since they are only a snapshot of two random days.

Breakfast skipping was self-reported using the following question out of the food choice questionnaire (FCQ) [23]: "I often skip breakfast" with seven answer categories ranging from "strongly disagree" to "strongly agree". This variable was further dichotomised by categorising adolescents as breakfast skipper if they answered "moderately agree" or "strongly agree".

\section{4-h dietary recall to assess dietary intake}

Dietary intake was assessed by two non-consecutive 24-h recalls. The 24-h recalls were collected by use of a computer-based self-administered tool, the HELENA-Dietary Intake Assessment Tool. This assessment tool is based on six meal occasions (breakfast, morning snacks, lunch, afternoon snacks, evening meal, evening snacks) referring to the previous day. Adolescents selected autonomously all the consumed foods and beverages from a standardised food list [24, 25]. Items not available in the list could be added by the participant at any moment. Consumed foods were translated to nutrients by use of the German Food Code and Nutrient Data Base (Bundeslebensmittelschlüssel, BLS, version II.3.1) [26]. Consequently, differences in fortification levels between countries were not taken into account. The Multiple Source Method was used to estimate the usual dietary intake of nutrients and foods [27]. This statistical modelling technique takes into account within-person variability and calculates usual intakes corrected for age, sex and study centre (city). Underreports 
were excluded from the analyses [28]. Underreporting was defined when the individual ratio of energy intake divided by the estimated basic metabolic rate was lower than 0.96 [29]. From the eligible participants, 294 underreporters were excluded, resulting in 1,250 subjects. Underreporters did not differ in sex or SES but had a higher BMI $z$-score $(p<0.001$; mean 0.98 vs. 0.19$)$ and were older $(p=0.001$; mean 14.9 vs. 14.7 years).

\section{Diet quality index}

Diet quality was calculated from the 24-h dietary recall using the Diet Quality Index for Adolescents with Meal index (DQI-AM), which assessed the compliance with the Flemish food-based dietary guidelines (FBDG) [30]. The DQI-AM consists of four pillars based on the principles of a healthy diet as provided in the Flemish FBDG: dietary quality, dietary diversity, dietary equilibrium and a meal index. The dietary quality indicates whether an individual makes optimal food quality choices within each food group: a preference group (e.g. fresh fruit, fish), a moderation group (e.g. white bread, minced meat) and a rest group (e.g. soft drinks, sweat snacks). Dietary diversity expresses the degree of variation in the diet and indicates whether a participant consumes at least one serving of food per day from each of the nine recommended food groups. Dietary equilibrium indicates to what extent the consumed portion sizes of the different food groups correspond with the recommended daily intakes. Finally, the meal index reflects the frequency of consumption of meals (which should include at least three main courses, as breakfast, lunch or dinner; higher index means more meals). The overall DQI-AM is the mean of the four pillars, with higher scores indicating higher diet quality. More detailed information on the technical aspects is provided elsewhere [31, 32].

\section{Body composition}

The protocol used to collect anthropometric data has been previously described [33]. Measurements were done while participants were barefoot and in underwear.

Weight was measured to the nearest $0.1 \mathrm{~kg}$ using electronic scales (Type SECA 861). Height was measured to the nearest $0.1 \mathrm{~cm}$ with the head aligned in the Frankfort plane using a telescopic height-measuring instrument (Type SECA 225). BMI was calculated as body weight in kilograms divided by the square of height in metres. In addition, BMI was adjusted for age and sex to give a BMI $z$-score using the British Growth Reference Data from the Child Growth Foundation [34], and overweight was classified following the International Obesity Task Force [35].

The triceps and subscapular skinfold thickness and waist and hip circumferences were measured on the left side of the body. A Holtain calliper (Crymmych, UK) was used to measure skinfold thickness to the nearest $0.2 \mathrm{~mm}$, and a non-elastic tape was used to measure circumference to the nearest $0.1 \mathrm{~cm}$ [33].

The waist-hip ratio was calculated as marker of central adiposity. A puberty-adjusted body fat $\%$ was calculated from the two skinfolds using the Slaughter formulae as marker of overall adiposity [36]. Pubertal status (stages I-V) was assessed by a medical doctor according to the scale developed by Tanner and Whitehouse [37], based on breast development and pubic hair status in females and genital and pubic hair development in males.

\section{Biomarkers for glucose and lipid profile}

Blood samples were collected in a randomly selected subset of the total HELENA study population by venipuncture at school between 8 and 10 A.M. after a 10-h overnight fast. Blood was collected in tubes for serum (blood lipid profile) and heparinised tubes for plasma (insulin), centrifuged at 3,500 rpm, aliquoted and transported at $4-7{ }^{\circ} \mathrm{C}$ (for a maximum of $14 \mathrm{~h}$ ) to the central laboratory in Bonn (Germany). Triglycerides (TG), total cholesterol (TC), high-density lipoprotein cholesterol (HDL), low-density lipoprotein cholesterol (LDL), very low-density lipoprotein cholesterol (VLDL), lipoprotein A (LpA) and glucose were measured using enzymatic methods (Dade Behring, Schwalbach, Germany) from fresh serum within $24 \mathrm{~h}$ of blood extraction. Heparin plasma was stored at $-80{ }^{\circ} \mathrm{C}$ until assayed. Insulin concentrations were measured using an Immulite 2000 analyser (DPC Bierman GmbH, Bad Nauheim, Germany).

The following indices of lipid status were calculated: non-HDL/HDL, LDL/HDL, TC/HDL, LDL corrected for LpA, and TG/HDL. Insulin resistance was measured by calculating the homoeostasis model assessment (HOMA) index as follows: fasting insulin $(\mu \mathrm{IU} / \mathrm{mL}) \times$ fasting glucose $(\mathrm{mg} / \mathrm{dL}) / 405$ [38].

\section{Statistics}

Analyses were performed with PASW Statistical Program version 19.0 (SPSS Inc, IBM, IL, USA). Two-sided level of significance was set at $p<0.05$. Non-normal data were transformed using the logarithmic or square root transformation to perform analyses, but data were back-transformed in the original units for representation. The regression analyses were all corrected for age, sex, SES, city and breakfast skipping. Estimated marginal means from the regression were used for the graphs. For significance levels between consecutive categories of RTEC consumption, the "repeated" contrasts were run with RTEC non-consumers as reference category. Socio-demographic differences (age, 
sex, city and SES) between different RTEC consumption groups were examined by means of a logistic regression with RTEC consumption as outcome. All covariates were included simultaneously to test their independent influence.

Differences in overall daily nutrient intakes and DQI were examined between RTEC consumer categories by linear regression corrected for age, sex, city, SES and breakfast skipping. Apart from energy, the following nutrients were studied: fat, protein, carbohydrates (also separate for glucose, fructose, galactose, sucrose, lactose, maltose and polysaccharides), fibre (also separately for water soluble and water insoluble fibres), minerals (calcium, iron, magnesium, phosphorus, potassium, sodium and zinc) and vitamins A, B1 (thiamine), B2 (riboflavin), B3 (niacin), B5 (pantothenic acid), B6 (pyridoxine), B7(biotin), B9 (folic acid), B12 (cobalamin), C, D, E, K.

The daily prevalence of milk/yoghurt and fruit intake in the different RTEC consumer categories was examined using $\chi^{2}$ statistics. The daily quantity of milk/yoghurt and fruit intake was examined with linear regression, excluding those that did not consume milk/yoghurt or fruit. Logistic regression was used to detect differences in fulfilling the daily intake recommendation for milk and fruit, based on the age- and sex-specific recommendations for European adolescents [39].

Linear regression was used to test the association of RTEC consumption with body composition (BMI, body fat $\%$, waist circumference and waist-hip ratio). The linear regressions with glucose homoeostasis (insulin, glucose and HOMA-index) and blood lipid (TC, LDL, HDL, VLDL, non-HDL/HDL, LDL/HDL, TC/HDL, LDL corrected for LpA cholesterol, TG or TG/HDL) as outcome were additionally adjusted for BMI $z$-scores and physical activity. A logistic regression was run to determine RTEC consumption difference in their risk for overweight.

\section{Results}

\section{Descriptive data}

In total, 1,215 adolescents (44 \% boys, $12.5-17.5$ years old) with valid FFQ and two-day 24-h recall data were included in the analyses. Based on the FFQ, $29 \%$ was classified as breakfast skipper and $65 \%$ was classified as RTEC consumer (defined as RTEC intake once a week or more).

RTEC consumers were younger than RTEC non-consumers (14.7 vs. 15 years, $p=0.01)$. An equal number of boys and girls was RTEC consumers, but boys were more often daily consumers (36\%) than girls $(29 \%)(p=0.031)$. RTEC consumption (especially frequent consumption) was more frequent in adolescents from the lowest FAS families $(p=0.002)$. No differences were seen depending on parental education. Although the prevalence of RTEC consumption was different between study centres (Athens in Greece $76 \%$, Dortmund in Germany $64 \%$, Ghent in Belgium $63 \%$, Lille in France $69 \%$, Stockholm in Sweden $63 \%$, Vienna in Austria $58 \%$, Zaragoza in Spain $67 \%$ ), no significant differences were seen after correction for sex, age and FAS $(p=0.549)$. Breakfast skipping was less prevalent in RTEC consumers (25.1 vs. $36.7 \%$ in RTEC non-consumers, $p<0.001)$ and was lowest in the Northern region (16 vs. 35 and $31 \%$ ).

For descriptive purposes, macronutrient and micronutrient intake were compared with the recommended intakes by the FAO/WHO [40, 41]. In our total population $(N=1,215)$, the adolescents had a mean fat intake of 33 percentage of energy intake $(E \%)$, a mean carbohydrate intake of $50 \mathrm{E} \%$ and a mean protein intake of $16 \mathrm{E} \%$. Only $8 \%$ of the adolescents had a higher carbohydrate intake than recommended ( $>60 E \%)$, but $63 \%$ of the adolescents had a high fat intake ( $>35 E \%)$, especially in the Southern region. For fibre, $34.3 \%$ had a low intake ( $<20 \mathrm{~g} /$ day), especially in the Southern region. For most vitamins and minerals, the recommended intake was achieved. This was not the case for vitamin D since none of the adolescents reached the recommended 5,000 ng/day. For calcium, only $10.8 \%$ reached the recommended intake $(1,300 \mathrm{mg} / \mathrm{day})$, especially in the Western/central region where only $5.4 \%$ reached this recommendation. For iron, $51.2 \%$ reached the sex- and age-specific recommended intake $(67.9 \%$ of the boys and $38 \%$ of the girls, without regional differences).

\section{Dietary intake differences}

The DQI and its four separate subscales over the two 24-h recalls were compared between RTEC consumers and RTEC non-consumers (Fig. 1). The total DQI score gave the same significances as the quality subscale. On diet quality, equilibrium and meal index, RTEC non-consumers scored lower than the frequent and daily RTEC consumers. On diet diversity, RTEC non-consumers scored lower than the frequent RTEC consumers and there was a trend for lower diversity in daily versus frequent RTEC consumers.

Whole day nutrient intake was compared between RTEC consumption groups in Table 1. The mean 24-h intake for total energy, fat (and the separate saturated and unsaturated fats), carbohydrates (and the separate mono-, diand polysaccharides), protein and fibre (and the separate water soluble and insoluble fibres) was not significantly different between RTEC non-consumers and the different RTEC consumer groups, also not when comparing $E \%$. Nevertheless, RTEC consumers had a different micronutrient intake profile. As the frequency of RTEC consumption increased, a higher intake of calcium $(p=0.032)$, phosphorus $(p=0.005)$, potassium $(p=0.007)$, vitamin 

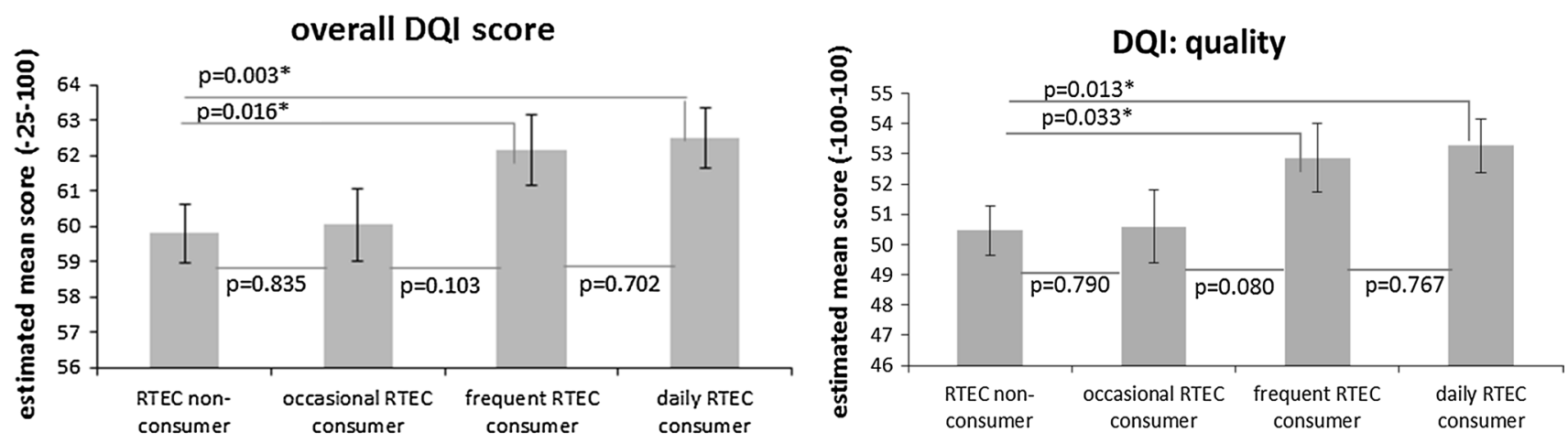

\section{DQI: equilibrium}
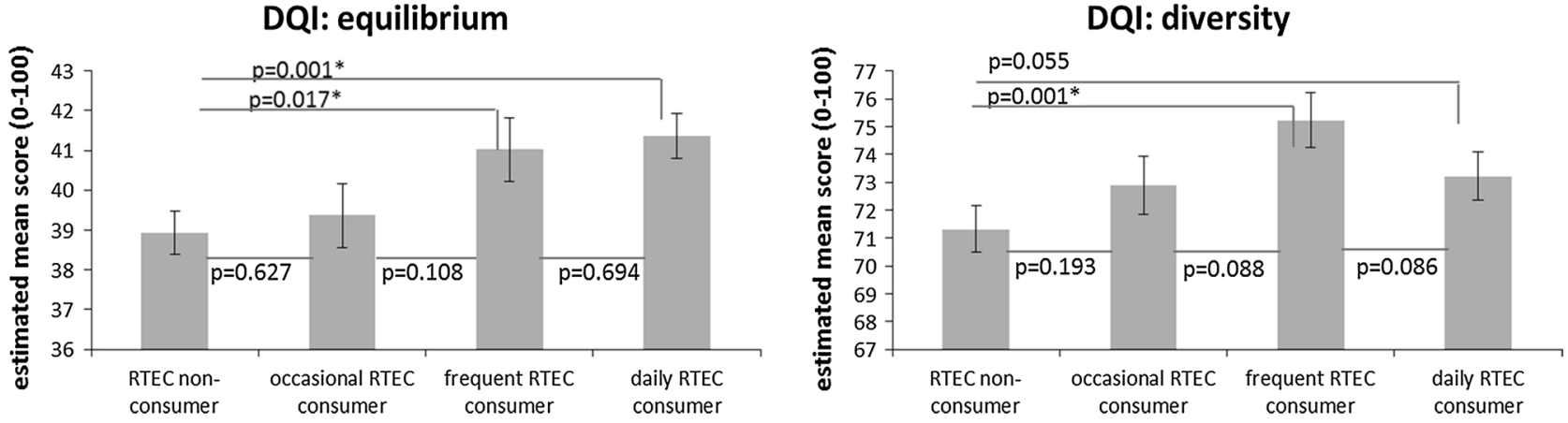

DQI: meal index

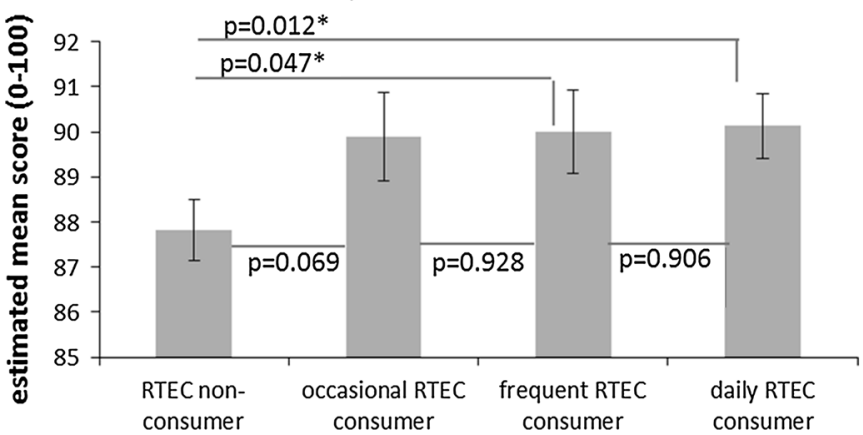

Fig. 1 Differences in diet quality index (DQI) subscales between ready-to-eat-cereals (RTEC) consumption groups $(N=425,190,209$ or 391, respectively). Estimated marginal means and standard errors after correction for age, sex, city, socio-economic status and breakfast

B2 $(p<0.001), \mathrm{B} 5(p=0.005), \mathrm{B} 7(p<0.001)$ and $\mathrm{D}$ $(p=0.006)$ was observed.

Table 2 shows the percentage consumers and quantity of milk/yoghurt and fruit consumption in different RTEC consumption groups. RTEC consumers had a more frequent intake of milk/yoghurt and fruit $(p<0.001)$. A second analysis focused on the quantity of milk/yoghurt and fruit intake in those that consumed these items. The RTEC consumer groups did not differ in the quantity of fruit intake. RTEC consumers had a higher quantity $(200 \mathrm{ml} /$ day more) of milk/yoghurt intake over the whole day than nonconsumers $(p<0.001)$. Same results were seen for the recommendation fulfilment of the daily milk and fruit intake

skipping are given. $p$ values are retrieved by post hoc analysis on the linear regression: comparing all groups with the RTEC non-consumers and with the adjacent group. *significant at $p<0.05$

when using logistic regression: no difference in fulfilment for fruit intake $(p=0.705)$ between the consumer groups, but daily RTEC consumers had 2.65 times more chance to fulfil the daily milk intake recommendation than RTEC non-consumers $(p<0.001$; not significant if compared with occasional and frequent consumers).

Body composition

Daily RTEC consumers showed a better body composition than RTEC non-consumers, i.e. they had lower BMI $z$-scores (0.37 vs. 0.59$)$, body fat $\%$ (23 vs. $25 \%$ ) and waist circumference (70.8 vs. $72.3 \mathrm{~cm}$ ) (Fig. 2). Daily RTEC 
Table 1 Differences in daily macro- and micronutrients intake between ready-to-eat-cereals (RTEC) consumption groups

\begin{tabular}{|c|c|c|c|c|c|}
\hline & $\begin{array}{l}\text { RTEC non-consumer } \\
(N=425)\end{array}$ & $\begin{array}{l}\text { Occasional RTEC con- } \\
\text { sumer }(N=190)\end{array}$ & $\begin{array}{l}\text { Frequent RTEC consumer } \\
(N=209)\end{array}$ & $\begin{array}{l}\text { Daily RTEC consumer } \\
(N=391)\end{array}$ & $p$ \\
\hline Energy (kcal) & 2,347 & 2,419 & 2,359 & 2,378 & 0.553 \\
\hline Fat $(\mathrm{g})$ & 87 & 92 & 88 & 88 & 0.308 \\
\hline Simple unsaturated & 33.3 & 35.8 & 33.5 & 33.6 & 0.108 \\
\hline $\begin{array}{l}\text { Multiple unsatu- } \\
\text { rated }\end{array}$ & 12.8 & 13.1 & 13.1 & 12.7 & 0.824 \\
\hline Saturated & 37.6 & 40.6 & 38.6 & 38.7 & 0.129 \\
\hline Cholesterol & 0.36 & 0.38 & 0.36 & 0.36 & 0.150 \\
\hline Protein $(\mathrm{g})$ & 91 & 93 & 91 & 93 & 0.724 \\
\hline Carbohydrates (g) & 283 & 287 & 285 & 288 & 0.839 \\
\hline Monosaccharides & 54.1 & 55.2 & 56.3 & 50.9 & 0.730 \\
\hline Disaccharides & 89.5 & 95.6 & 90.5 & 93.5 & 0.108 \\
\hline Polysaccharides & 147 & 149 & 148 & 151 & 0.125 \\
\hline Fibre $(\mathrm{g})$ & 18.5 & 18.7 & 18.6 & 19.3 & 0.394 \\
\hline Calcium (mg) & 584 & 677 & 610 & 711 & $0.032 *$ \\
\hline Iron $(\mu \mathrm{g})$ & 12,797 & 13,056 & 12,797 & 12,797 & 0.052 \\
\hline Magnesium (mg) & 306 & 317 & 311 & 325 & 0.862 \\
\hline Phosphorus (mg) & 1,333 & 1,384 & 1,376 & 1,436 & $0.005 *$ \\
\hline Potassium (mg) & 2,607 & 2,705 & 2,722 & 2,819 & $0.007 *$ \\
\hline Sodium (mg) & 2,018 & 2,061 & 2,126 & 2,094 & 0.256 \\
\hline Zinc $(\mu \mathrm{g})$ & 11,897 & 12,271 & 11,896 & 12,136 & 0.472 \\
\hline Vit A $(\mu \mathrm{g})$ & 993 & 1,048 & 1,032 & 1,016 & 0.406 \\
\hline Vit B1 $(\mu \mathrm{g})$ & 1,234 & 1,259 & 1,239 & 1,246 & 0.893 \\
\hline Vit B2 $(\mu \mathrm{g})$ & 1,477 & 1,577 & 1,580 & 1,667 & $<0.001 *$ \\
\hline Vit B3 $(\mu \mathrm{g})$ & 14,765 & 15,169 & 14,765 & 14,676 & 0.742 \\
\hline Vit B5 $(\mu \mathrm{g})$ & 4,699 & 4,920 & 4,905 & 5,070 & $0.005^{*}$ \\
\hline Vit B6 $(\mu \mathrm{g})$ & 1,661 & 1,694 & 1,701 & 1,701 & 0.719 \\
\hline Vit B7 $(\mu \mathrm{g})$ & 40 & 43 & 43 & 44 & $<0.001^{*}$ \\
\hline Vit B9 $(\mu \mathrm{g})$ & 198 & 207 & 204 & 206 & 0.331 \\
\hline Vit B12 (ng) & 5,523 & 5,697 & 5,795 & 5,657 & 0.474 \\
\hline Vit C (mg) & 84 & 87 & 89 & 90 & 0.486 \\
\hline Vit D (ng) & 1,833 & 2,036 & 2,048 & 2,027 & $0.006^{*}$ \\
\hline Vit $E(\mu \mathrm{g})$ & 9,730 & 10,067 & 10,037 & 9,799 & 0.532 \\
\hline Vit K $(\mu \mathrm{g})$ & 223 & 227 & 232 & 225 & 0.683 \\
\hline
\end{tabular}

Estimated marginal means after correction for age, sex, city, socio-economic status and breakfast skipping are given

$* p<0.05$

Table 2 Milk/yoghurt and fruit consumption in ready-to-eat-cereals (RTEC) consumption groups

\begin{tabular}{|c|c|c|c|c|c|}
\hline & $\begin{array}{l}\text { RTEC non-consumer } \\
(N=425)\end{array}$ & $\begin{array}{l}\text { Occasional RTEC con- } \\
\text { sumers }(N=190)\end{array}$ & $\begin{array}{l}\text { Frequent RTEC con- } \\
\text { sumer }(N=209)\end{array}$ & $\begin{array}{l}\text { Daily RTEC consumer } \\
(N=391)\end{array}$ & $p$ value difference \\
\hline \multicolumn{6}{|c|}{ Percentage consumers ${ }^{\mathrm{a}}$} \\
\hline Milk or yoghurt & $56.0 \%$ & $61.6 \%$ & $69.1 \%$ & $81.2 \%$ & $<0.001$ \\
\hline Fruit & $50.9 \%$ & $52.4 \%$ & $59.1 \%$ & $56.8 \%$ & 0.017 \\
\hline \multicolumn{6}{|l|}{ Quantity of intake ${ }^{b}$} \\
\hline $\begin{array}{l}\text { Milk or yoghurt } \\
\quad(\mathrm{ml})\end{array}$ & 321 & 431 & 429 & 552 & $<0.001$ \\
\hline Fruit (g) & 244 & 270 & 272 & 255 & 0.150 \\
\hline
\end{tabular}

${ }^{\mathrm{a}}$ Chi-square statistic; ${ }^{\mathrm{b}}$ estimated marginal means for regression after correction for age, sex, city, breakfast skipping and socio-economic status 

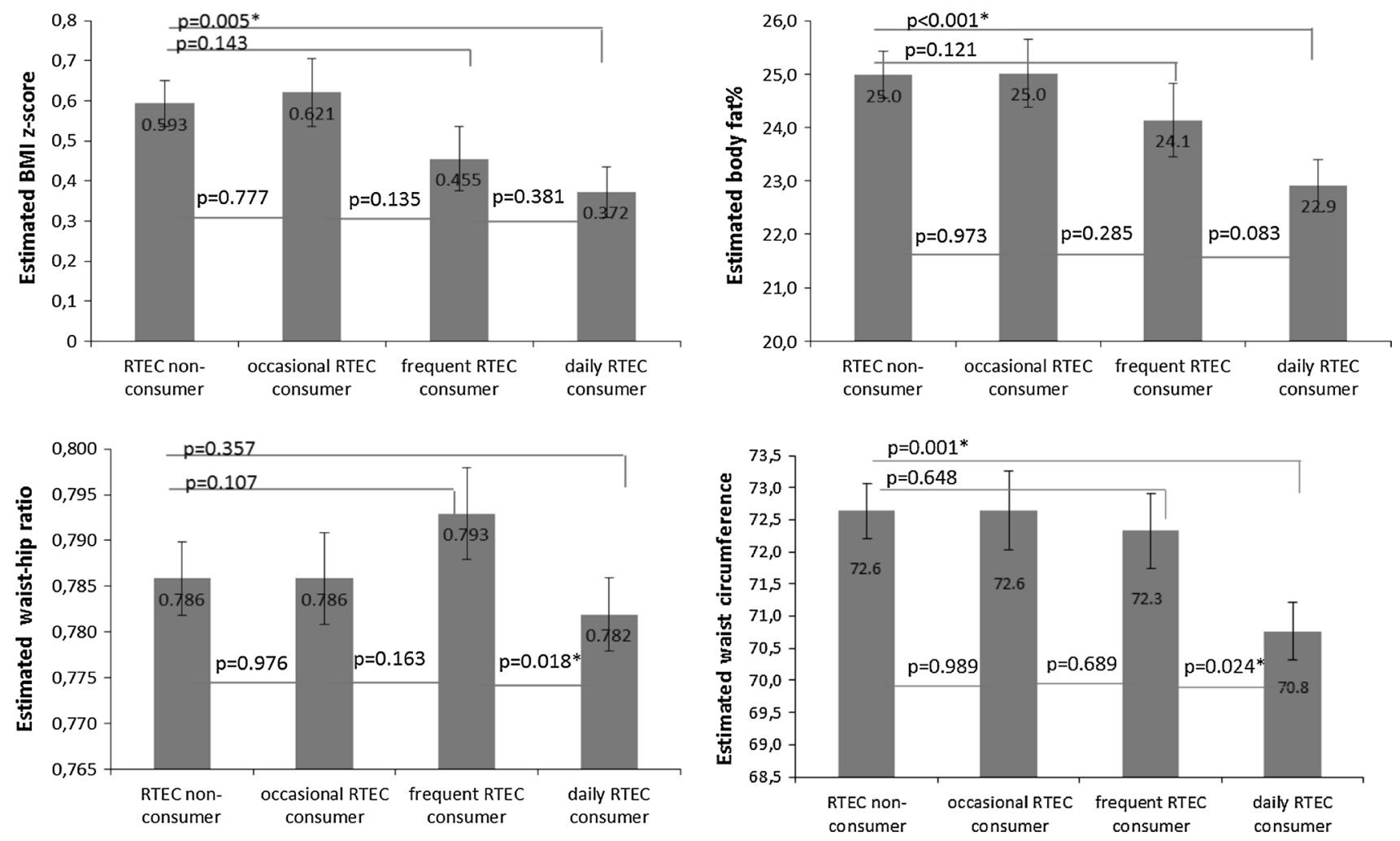

Fig. 2 Anthropometric differences depending on ready-to-eat-cereals (RTEC) consumption. Estimated marginal means and standard errors after correction for age, sex, city, SES and breakfast skipping are

given, comparing all groups with the RTEC non-consumers and with the adjacent group. *significant at $p<0.05$

consumers also had a lower waist circumference ( 70.8 vs. $72.3 \mathrm{~cm})$ and waist-hip ratio (0.78 vs. 0.79$)$ than frequent RTEC consumers. Other comparisons (e.g. non-RTEC consumers vs. occasional RTEC consumers) were not significant. Based on logistic regression, frequent and daily consumers had a lower risk for overweight than RTEC nonconsumers (40 and $57 \%$ less likely, respectively) (Fig. 3).

Glucose and lipid homoeostasis

Following published cut-offs [42, 43], $3 \%$ had a high TG level, $4 \%$ had a high LDL, $7 \%$ a low HDL level, $9 \%$ were pre-diabetic, none of the adolescents were diabetic. No differences in glucose and lipid status existed between RTEC consumers and the different RTEC non-consumption categories (see Table 3 for results of the main parameters). Glucose homoeostasis was weakly associated with DQI [44], but lipid homoeostasis was not (results not published).

\section{Discussion}

Our main aim was to analyse the association of RTEC consumption with dietary intake and nutritional status, for

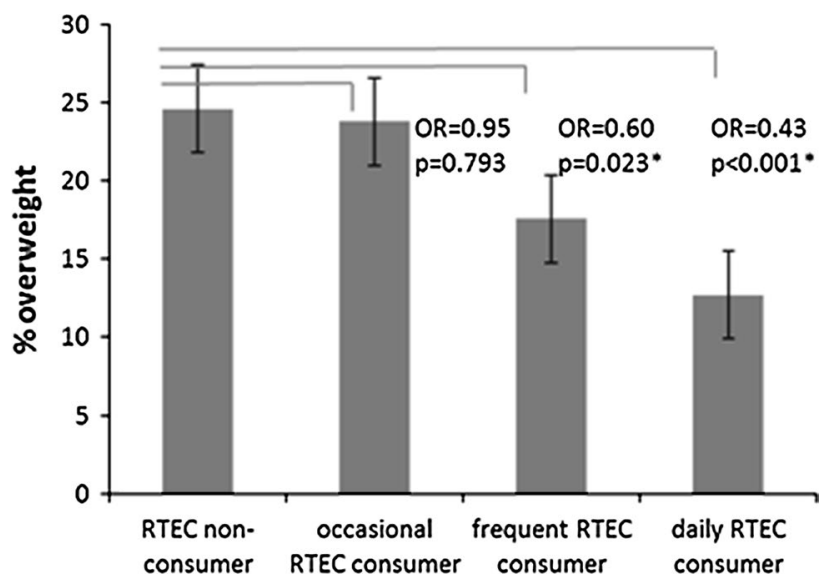

Fig. 3 Overweight percentage depending on ready-to-eat-cereals (RTEC) consumption. Means and standard deviations after correction for age, sex, city, SES and breakfast skipping are given. *significant at $p<0.05$

the first time in a multi-centric European study with harmonised methodology. RTEC consumption was associated with a higher consumption frequency of fruit and milk, a more beneficial daily micronutrient intake, a healthier DQI and less breakfast skipping. These results indicate better 
Table 3 Glucose- and lipid-metabolism parameters in ready-to-eat-cereal (RTEC) consumption groups

\begin{tabular}{|c|c|c|c|c|c|c|c|}
\hline & HOMA & Glucose (mg/dL) & Insulin $(\mu \mathrm{l} \mathrm{U} / \mathrm{mL})$ & HDL (mg/dL) & LDL (mg/dL) & VLDL (mg/dL) & Triglyceride (mg/dL) \\
\hline$p$ value & 0.782 & 0.070 & 0.546 & 0.117 & 0.395 & 0.174 & 0.173 \\
\hline RTEC non-consumer & 1.90 & 90.66 & 8.49 & 56.53 & 97.18 & 12.65 & 63.24 \\
\hline $\begin{array}{l}\text { Occasional RTEC } \\
\text { consumer }\end{array}$ & 1.92 & 88.17 & 9.21 & 59.55 & 93.77 & 12.64 & 63.18 \\
\hline $\begin{array}{l}\text { Frequent RTEC } \\
\text { consumer }\end{array}$ & 1.82 & 90.97 & 8.31 & 55.58 & 96.90 & 12.55 & 62.80 \\
\hline Daily RTEC consumer & 1.79 & 89.55 & 8.16 & 55.83 & 91.95 & 11.35 & 56.71 \\
\hline
\end{tabular}

Estimated marginal means after correction for age, sex, city, socio-economic status, breakfast skipping, BMI and physical activity are given HOMA homoeostasis model assessment, $H D L$ high-density lipoprotein, $L D L$ low-density lipoprotein, $V L D L$ very low-density lipoprotein

dietary habits in RTEC consumers. This finding was somewhat reflected in an improved body composition but not in a better glucose and lipid status. Moreover, we described socio-demographic determinants of RTEC consumption. Although regional differences were found in nutrient intake and breakfast skipping, with less frequent breakfast skipping in the northern region, no regional differences existed in the prevalence of RTEC consumption.

\section{Dietary intake}

The higher DQI in RTEC consumers reflects a more balanced, diverse diet and overall healthier food choice. A study in US adults also found a healthier DQI in RTEC consumers [45], but studies in children/adolescents did not consider the overall diet quality with a DQI and mainly focused on nutrient composition. The DQI has the advantage of capturing the human diet's complexity in a single value and consequently shows stronger correlations with health outcomes than individual nutrients or foods [11]. This better diet quality did not translate in a different macronutrient composition of the daily diet in our study (e.g. no difference in sugar content), but rather in a healthier micronutrient composition with higher intakes of calcium, phosphorus, potassium, vitamins B2, B5, B7 and D. As stated in the introduction, several studies already quoted the beneficial daily nutrient intake when consuming RTEC [3-10]. Although the reports regarding both, macronutrient intake and specific micronutrients, vary widely across studies, all studies consistently found a higher intake of calcium due to higher milk/dairy consumption in RTEC consumers. The other differences in micronutrient intake may be explained by the healthier DQI that reflects the overall diet and hence the intake of other nutritious food items. The higher vitamin D and calcium intake in RTEC consumers is important since the intake of these two micronutrients in our adolescents was below the international recommendations [46]. Nevertheless, the detected differences between the consumption groups are likely not big enough to realistically expect differences in health outcome measures. Also, this higher vitamin D intake is probably due to an overall healthier dietary intake and not due to the fortification of RTEC since there was no vitamin D fortification in the food composition database RTEC items.

RTEC could also contribute to a healthy diet via the accompanying food. Literature has shown higher milk/ yoghurt intake in RTEC consumers but mixed results concerning fruit intake $[6,10]$. Our study found a higher milk/ yoghurt consumption frequency and quantity in RTEC consumers over the day; daily RTEC consumers even had 2.65 times more chance to fulfil the daily milk intake recommendation [39]. RTEC consumers also had a higher fruit intake frequency, but when they consumed fruit, they consumed the same absolute amount as RTEC non-consumers. Consequently, RTEC consumers have a more routine habit of fruit consumption, independently of the portion size. These differences in milk/yoghurt and fruit consumption between RTEC consumers and non-consumers could again be indicative for a general healthier dietary routine in RTEC consumers.

\section{Nutritional status}

The higher DQI in RTEC consumers may contribute to a healthier body composition and serum biomarker status. Underlying hypotheses are the better energy regulation, the higher intake of healthy food items, the higher fibre intake, the lower fat intake, less breakfast skipping and more physical activity in RTEC consumers [12, 13, 47, 48]. In our study, the higher intake of healthy food items and a better diet quality were shown. Additionally, daily RTEC consumers were more physically active than non-consumers or occasional consumers (results not shown). Indeed, daily or frequent RTEC consumers had a better body composition than RTEC non-consumers (lower central and total fatness), but did not differ in glucose and lipid profile. As stated above, no differences in fat and fibre intake were observed between the RTEC consumption groups and this might be among others one 
explanation for the lack of association with these biomarkers. In this context, it should also be considered that no differentiation was made between different RTEC types (e.g. in fibre and monosaccharide composition and glycaemic index) and in the exact amount consumed. Apart from the dietary influences, these blood levels have a multi-factorial aetiology [47, 49], which was not fully analysed in this study.

\section{Strengths and limitations}

In contrast to existing studies, data were derived from a multi-centre European sample of adolescents. The extensive standardised information on diet (including detailed information of, e.g. carbohydrate subtypes), anthropometry and blood biomarkers makes it a valuable source for public health. RTEC analyses were corrected for breakfast skipping to examine the effect of RTEC consumption independently of breakfast skipping. Special focus was on diet with not only extensive information on daily nutrient composition, but also by using an all-integrating DQI and by focusing on milk and fruit intake (both prevalence and quantity). Besides, RTEC intake was linked with adolescents' body composition (BMI, waist and fat\%) and glucose and lipid status.

Nevertheless, several limitations exist. First of all, the cross-sectional nature of the data makes causal and unidirectional statements impossible. After all, RTEC intake is only one of the many foods and lifestyle factors that influence health. Secondly, no distinction could be made between different RTEC types due to lack of detail in the dietary recall. Consequently, no separation was possible in whole grain versus refined RTEC or on nutrient density (e.g. fat and sugars content), although a wide variety exists [1]. This might thwart the result interpretation since the different types could have different effects on nutrient intake, body composition and blood parameters [13]. Nevertheless, a recent report showed that adolescents' diet and weight did not vary by RTEC sugars content [50]. Thirdly, dietary information by our 24-h recall data is very detailed (e.g. information on quantity) but still has the disadvantage of being a snapshot of two random days. Finally, the hypotheses on glucose and lipid profile have less power to detect significant results. After all, the analyses were based on a smaller sample size $(N=387)$ because of the invasiveness of blood withdrawal and there is probably only a small concentration variation in our relatively healthy non-clinical population sample. Also here, we have the limitation that type and amount of RTEC was not known.

\section{Conclusion}

Although regional differences were found in nutrient intake and breakfast skipping, no regional differences existed in the prevalence of RTEC consumption after adjustment for relevant factors. For the first time in a multi-centre European adolescent sample, RTEC consumption has been associated with better dietary habits: a healthier daily diet quality, a more beneficial micronutrients intake (but no difference in macronutrients), a higher consumption frequency of milk and fruit and less breakfast skipping. As a result, the convenience of RTEC might help in the prevention of breakfast skipping. This better diet was well aligned with a more desirable body composition, but not with improved glucose and lipid statuses. Still, more research is needed on the potential health impact of different RTEC types using a longitudinal or interventional study design. In doing this, the current study results emphasise the importance of using a diet quality index in addition to measuring solely macroand micro-nutrient intake.

Acknowledgments Many thanks to Anke Carstensen and Petra Pickert for their contribution to laboratory work and to Inge Huybrechts for designing the diet quality index. The HELENA Study was carried out with the financial support of the European Community Sixth RTD Framework Programme (Contract FOODCT-2005-007034). The writing group takes sole responsibility for the content of this article. The European Community is not liable for any use that may be made of the information contained therein. An unconditional grant from Cereal Partners Worldwide S.A. was received for performing the statistical analyses in this manuscript.

Conflict of interest F. T. and B. R. were affiliated at Cereal Partners Worldwide S.A. at the time this analysis was conducted. This did not influence the scientific integrity.

Ethical standard The study was performed following the ethical guidelines of the Declaration of Helsinki 1964 and its later amendments. All study participants and their parents provided a signed informed consent form.

\section{References}

1. Goglia R, Spiteri M, Menard C, Dumas C, Combris P, Labarbe B, Soler LG, Volatier JL (2010) Nutritional quality and labelling of ready-to-eat breakfast cereals: the contribution of the French observatory of food quality. Eur J Clin Nutr 64(Suppl 3):S20S25. doi:10.1038/ejen.2010.205

2. Serra-Majem L (2001) Vitamin and mineral intakes in European children. Is food fortification needed? Public Health Nutr 4:101-107

3. Albertson AM, Affenito SG, Bauserman R, Holschuh NM, Eldridge AL, Barton BA (2009) The relationship of ready-toeat cereal consumption to nutrient intake, blood lipids, and body mass index of children as they age through adolescence. J Am Diet Assoc 109:1557-1565. doi:10.1016/j.jada.2009.06.363

4. Barton BA, Eldridge AL, Thompson D, Affenito SG, StriegelMoore RH, Franko DL, Albertson AM, Crockett SJ (2005) The relationship of breakfast and cereal consumption to nutrient intake and body mass index: the national heart, lung, and blood institute growth and health study. J Am Diet Assoc 105:13831389. doi:10.1016/j.jada.2005.06.003 
5. Deshmukh-Taskar PR, Nicklas TA, O'Neil CE, Keast DR, Radcliffe JD, Cho S (2010) The relationship of breakfast skipping and type of breakfast consumption with nutrient intake and weight status in children and adolescents: the national health and nutrition examination survey 1999-2006. J Am Diet Assoc 110:869-878. doi:10.1016/j.jada.2010.03.023

6. Gibson S (2003) Micronutrient intakes, micronutrient status and lipid profiles among young people consuming different amounts of breakfast cereals: further analysis of data from the national diet and nutrition survey of young people aged 4 to 18 years. Public Health Nutr 6:815-820

7. Grieger JA, Cobiac L (2012) Comparison of dietary intakes according to breakfast choice in Australian boys. Eur J Clin Nutr 66:667-672. doi:10.1038/ejcn.2011.220

8. Kafatos A, Linardakis M, Bertsias G, Mammas I, Fletcher R, Bervanaki $F$ (2005) Consumption of ready-to-eat cereals in relation to health and diet indicators among school adolescents in Crete, Greece. Ann Nutr Metab 49:165-172. doi:10.1159/000086880

9. Song WO, Chun OK, Kerver J, Cho S, Chung CE, Chung SJ (2006) Ready-to-eat breakfast cereal consumption enhances milk and calcium intake in the US population. J Am Diet Assoc 106:1783-1789. doi:10.1016/j.jada.2006.08.015

10. van den Boom A, Serra-Majem L, Ribas L, Ngo J, Perez-Rodrigo C, Aranceta J, Fletcher R (2006) The contribution of ready-to-eat cereals to daily nutrient intake and breakfast quality in a Mediterranean setting. J Am Coll Nutr 25:135-143

11. Kant AK (1996) Indexes of overall diet quality: a review. J Am Diet Assoc 96:785-791. doi:10.1016/S0002-8223(96)00217-9

12. de la Hunty A, Gibson S, Ashwell M (2013) Does regular breakfast cereal consumption help children and adolescents stay slimmer? A systematic review and meta-analysis. Obes Facts 6:7085. doi: $10.1159 / 000348878$

13. Kosti RI, Panagiotakos DB, Zampelas A (2010) Ready-to-eat cereals and the burden of obesity in the context of their nutritional contribution: are all ready-to-eat cereals equally healthy? A systematic review. Nutr Res Rev 23:314-322. doi:10.1017/ S095442241000020x

14. Albertson AM, Thompson D, Franko DL, Holschuh NM, Bauserman R, Barton BA (2009) Prospective associations among cereal intake in childhood and adiposity, lipid levels, and physical activity during late adolescence. J Am Diet Assoc 109:1775-1780. doi:10.1016/j.jada.2009.07.004

15. Deshmukh-Taskar P, Nicklas TA, Radcliffe JD, O'Neil CE, Liu Y (2012) The relationship of breakfast skipping and type of breakfast consumed with overweight/obesity, abdominal obesity, other cardiometabolic risk factors and the metabolic syndrome in young adults. The National Health and Nutrition Examination Survey (NHANES): 1999-2006. Public Health Nutr 1-10. doi:10.1017/S1368980012004296

16. Pereira M, Erickson E, McKee P, Schrankler K, Raatz SK, Lytle LA, Pellegrini AD (2011) Breakfast frequency and quality may affect glycemia and appetite in adults and children. J Nutr 141:163-168. doi:10.3945/jn.109.114405

17. Ruxton CH, Kirk TR (1997) Breakfast: a review of associations with measures of dietary intake, physiology and biochemistry. $\mathrm{Br}$ J Nutr 78:199-213

18. Hallstrom L, Labayen I, Ruiz JR, Patterson E, Vereecken CA, Breidenassel C, Gottrand F, Huybrechts I, Manios Y, Mistura L, Widhalm K, Kondaki K, Moreno LA, Sjostrom M, Group HS (2013) Breakfast consumption and CVD risk factors in European adolescents: the HELENA (Healthy Lifestyle in Europe by Nutrition in Adolescence) study. Public Health Nutr 16:1296-1305. doi:10.1017/S1368980012000973

19. Moreno LA, De Henauw S, Gonzalez-Gross M, Kersting M, Molnar D, Gottrand F, Barrios L, Sjostrom M, Manios Y, Gilbert CC, Leclercq C, Widhalm K, Kafatos A, Marcos A, Grp
HS (2008) Design and implementation of the healthy lifestyle in Europe by nutrition in adolescence cross-sectional study. Int $\mathbf{J}$ Obes 32:S4-S11. doi:10.1038/Ijo.2008.177

20. Moreno LA, Gonzalez-Gross M, Kersting M, Molnar D, de Henauw S, Beghin L, Sjostrom M, Hagstromer M, Manios Y, Gilbert CC, Ortega FB, Dallongeville J, Arcella D, Warnberg J, Hallberg M, Fredriksson H, Maes L, Widhalm K, Kafatos AG, Mar$\cos$ A, Group HS (2008) Assessing, understanding and modifying nutritional status, eating habits and physical activity in European adolescents: the HELENA (Healthy Lifestyle in Europe by Nutrition in Adolescence) study. Public Health Nutr 11:288-299. doi:10.1017/S1368980007000535

21. Currie C, Molcho M, Boyce W, Holstein B, Torsheim T, Richter M (2008) Researching health inequalities in adolescents: the development of the health behaviour in school-aged children (HBSC) family affluence scale. Soc Sci Med 66:1429-1436. doi:10.1016/j.socscimed.2007.11.024

22. Vereecken CA, Maes L (2003) A Belgian study on the reliability and relative validity of the health behaviour in school-aged children food-frequency questionnaire. Public Health Nutr 6:581-588

23. Gilbert CC, Hegyi A, Sanchez MJ, Hall G, Fontaine L, Kuti T (2008) Qualitative research exploring food choices and preferences of adolescents in Europe. HELENA Deliv 11.1

24. Vereecken CA, Covents M, Sichert-Hellert W, Alvira JM, Le Donne C, De Henauw S, De Vriendt T, Phillipp MK, Beghin L, Manios Y, Hallstrom L, Poortvliet E, Matthys C, Plada M, Nagy E, Moreno LA, Group HS (2008) Development and evaluation of a self-administered computerized 24-h dietary recall method for adolescents in Europe. Int J Obes 32(Suppl 5):S26-S34. doi:10.1 038/ijo.2008.180

25. Vereecken CA, Covents M, Matthys C, Maes L (2005) Young adolescents' nutrition assessment on computer (YANA-C). Eur J Clin Nutr 59:658-667. doi:10.1038/sj.ejen.1602124

26. Dehne LI, Klemm C, Henseler G, Hermann-Kunz E (1999) The German Food Code and Nutrient Data Base (BLS II.2). Eur J Epidemiol 15:355-359

27. Haubrock J, Hartigg U, Souverein O, Boeing H (2010) An improved statistical tool for estimating usual intake distributions: the multiple source method (MSM). Arch Public Health 68:14-15

28. Vandevijvere S, Geelen A, Gonzalez-Gross M, Van't Veer P, Dallongeville J, Mouratidou T, Dekkers A, Bornhorst C, Breidenassel C, Crispim SP, Moreno LA, Cuenca-Garcia M, Vyncke K, Beghin L, Grammatikaki E, De Henauw S, Catasta G, Hallstrom L, Sjostrom M, Warnberg J, Esperanza L, Slimani N, Manios Y, Molnar D, Gilbert CC, Kafatos A, Stehle P, Huybrechts I (2012) Evaluation of food and nutrient intake assessment using concentration biomarkers in European adolescents from the Healthy Lifestyle in Europe by Nutrition in Adolescence study. Br J Nutr 1-12. doi:10.1017/S0007114512002012

29. Black AE (2000) Critical evaluation of energy intake using the Goldberg cut-off for energy intake: basal metabolic rate. A practical guide to its calculation, use and limitations. Int $\mathrm{J}$ Obes 24:1119-1130. doi:10.1038/sj.ijo.0801376

30. VIGeZ (2006) De actieve voedingsdriehoek: een praktische voedings- en beweeggids (the active food pyramid: a practical guide to diet and physical activity). Vlaams Instituut voor Gezondheidspromotie en Ziektepreventie (VIGeZ), Brussels

31. Huybrechts I, Vereecken C, De Bacquer D, Vandevijvere S, Van Oyen H, Maes L, Vanhauwaert E, Temme L, De Backer G, De Henauw S (2010) Reproducibility and validity of a diet quality index for children assessed using a FFQ. Br J Nutr 104:135-144. doi:10.1017/S0007114510000231

32. Vyncke K, Cruz Fernandez E, Fajo-Pascual M, Cuenca-Garcia M, De Keyzer W, Gonzalez-Gross M, Moreno LA, Beghin L, Breidenassel C, Kersting M, Albers U, Diethelm K, Mouratidou 
T, Grammatikaki E, De Vriendt T, Marcos A, Bammann K, Bornhorst C, Leclercq C, Manios Y, Dallongeville J, Vereecken C, Maes L, Gwozdz W, Van Winckel M, Gottrand F, Sjostrom M, Diaz LE, Geelen A, Hallstrom L, Widhalm K, Kafatos A, Molnar D, De Henauw S, Huybrechts I (2012) Validation of the diet quality index for Adolescents by comparison with biomarkers, nutrient and food intakes: the HELENA study. Br J Nutr 1-12. doi:10.1017/S000711451200414X

33. Nagy E, Vicente-Rodriguez G, Manios Y, Beghin L, Iliescu C, Censi L, Dietrich S, Ortega FB, De Vriendt T, Plada M, Moreno LA, Molnar D, Group HS (2008) Harmonization process and reliability assessment of anthropometric measurements in a multicenter study in adolescents. Int J Obes 32(Suppl 5):S58-S65. doi: 10.1038/ijo.2008.184

34. Cole TJ, Freeman JV, Preece MA (1995) Body-mass index reference curves for the UK, 1990. Arch Dis Child 73:25-29

35. Cole TJ, Bellizzi MC, Flegal KM, Dietz WH (2000) Establishing a standard definition for child overweight and obesity worldwide: international survey. Br Med J (Clin Res Ed) 320:1240-1243

36. Slaughter MH, Lohman TG, Boileau RA, Horswill CA, Stillman RJ, Van Loan MD, Bemben DA (1988) Skinfold equations for estimation of body fatness in children and youth. Hum Biol 60:709-723

37. Tanner JM, Whitehouse RH (1976) Clinical longitudinal standards for height, weight, height velocity, weight velocity, and stages of puberty. Arch Dis Child 51:170-179

38. Matthews DR, Hosker JP, Rudenski AS, Naylor BA, Treacher DF, Turner RC (1985) Homeostasis model assessment: insulin resistance and beta-cell function from fasting plasma glucose and insulin concentrations in man. Diabetologia 28:412-419

39. Kersting M, Alexy U, Clausen K (2005) Using the concept of food based dietary guidelines to develop an optimized mixed diet (OMD) for German children and adolescents. J Pediatr Gastroenterol Nutr 40:301-308. doi:10.1097/01. Mpg.0000153887.19429.70

40. EFSA (2010) Scientific opinion on dietary reference values for carbohydrates and dietary fibre. EFSA J 8:1462

41. WHO/FAO (2004) Vitamin and mineral requirements in human nutrition
42. Jolliffe CJ, Janssen I (2006) Distribution of lipoproteins by age and gender in adolescents. Circulation 114:1056-1062. doi:10.11 61/CIRCULATIONAHA.106.620864

43. American Diabetes Association (2014) Diagnosis and classification of diabetes mellitus. Diabetes Care 37(Suppl 1):S81-S90. doi:10.2337/dc14-S081

44. Jimenez-Pavon D, Sese MA, Huybrechts I, Cuenca-Garcia M, Palacios G, Ruiz JR, Breidenassel C, Leclercq C, Beghin L, Plada M, Manios Y, Androutsos O, Dallongeville J, Kafatos A, Widhalm K, Molnar D, Moreno LA (2013) Dietary and lifestyle quality indices with/without physical activity and markers of insulin resistance in European adolescents: the HELENA study. Br J Nutr 110:1919-1925. doi:10.1017/S0007114513001153

45. Deshmukh-Taskar PR, Radcliffe JD, Liu Y, Nicklas TA (2010) Do breakfast skipping and breakfast type affect energy intake, nutrient intake, nutrient adequacy, and diet quality in young adults? NHANES 1999-2002. J Am Coll Nutr 29:407-418

46. Gonzalez-Gross M, Valtuena J, Breidenassel C, Moreno LA, Ferrari M, Kersting M, De Henauw S, Gottrand F, Azzini E, Widhalm K, Kafatos A, Manios Y, Stehle P, Group HS (2012) Vitamin $\mathrm{D}$ status among adolescents in Europe: the healthy lifestyle in Europe by nutrition in adolescence study. Br J Nutr 107:755-764. doi:10.1017/S0007114511003527

47. Lewis B (1990) Diet and exercise as regulators of lipid risk-factors. Drugs 40:19-25

48. Parillo M, Riccardi G (2004) Diet composition and the risk of type 2 diabetes: epidemiological and clinical evidence. Br J Nutr 92:7-19. doi:10.1079/BJN20041117

49. Qi L, Hu FB, Hu G (2008) Genes, environment, and interactions in prevention of type 2 diabetes: a focus on physical activity and lifestyle changes. Curr Mol Med 8:519-532

50. Albertson AM, Thompson DR, Franko DL, Holschuh NM (2011) Weight indicators and nutrient intake in children and adolescents do not vary by sugar content in ready-to-eat cereal: results from national health and nutrition examination survey 2001-2006. Nutr Res 31:229-236. doi:10.1016/j.nutres.2011.03.004 